\title{
Study of Ethyl Cellulose Based Sustained Release Microspheres of Naproxen Sodium
}

\section{Kowshik Sarkar ${ }^{1}$, Sams Mohammad Anowar Sadat ${ }^{2}$, Md. Saiful Islam ${ }^{3}$ and Reza-ul J alii ${ }^{3}$}

\author{
${ }^{1}$ Department of Pharmacy, The University of Asia Pacific, House-73; Road-5/A; Dhanmondi R/A, Dhaka-1209, \\ Bangladesh \\ ${ }^{2}$ Incepta Pharmaceuticals Ltd., Dhaka, Bangladesh \\ ${ }^{3}$ Department of Pharmaceutical Technology, Faculty of Pharmacy, University of Dhaka, Dhaka-1000, \\ Bangladesh
}

\begin{abstract}
The present study was conducted to prepare sustained release microspheres of naproxen sodium using ethyl cellulose (Ethocel $20 \mathrm{cps}$ ) polymer. Three different plasticizers namely polyethyleneglycol 600 (PEG 600), polyethyleneglycol 6000 (PEG 6000) and triethyl citrate (TEC) were used at 10\% (wt/wt) and 40\% (wt/wt) level of the drug content. Prepared microspheres were characterized with respect to drug loading, microsphere particle size, microsphere surface morphology and release behavior. Surface morphology of the microspheres was examined in a scanning electron microscope. Drug release was observed in phosphate buffer solution of pH 6.8 for 8 hours. At 10\% level of the plasticizers, percent release was $93.36 \%, 93.02 \%$ and 92.67\% for PEG 600, PEG 6000 and TEC respectively after 8 hours. On the other hand, at $40 \%$ level, percent release was $81.12 \%, 70.06 \%$ and $51.12 \%$ for PEG 600, PEG 6000 and TEC respectively after the same duration. Release mechanisms followed case I or fickian model.
\end{abstract}

Key words: Naproxen sodium, Ethocel 20 cps, Sustained release, Microsphere, Scanning electron microscope.

\section{INTRODUCTION}

Naproxen sodium (NS) has been proved to be effective in both experimental and clinical pain like rheumatoid arthritis, osteoarthritis, juvenile arthritis and acute gout without any serious cardiovascular or respiratory side effects. ${ }^{1,2}$ The drug is lipid soluble, practically insoluble at low $\mathrm{pH}$ and freely soluble at high $\mathrm{pH}$. One of the most important commonly used methods for controlling drug release is to form a matrix system with the help of hydrophilic, inert and hydrophobic polymers. Ethyl cellulose (EC) is hydrophobic polymer and is essentially tasteless, odorless, colorless and physiologically and pharmacologically inert. It has been extensively used as a pharmaceutical solid vehicle in preparing microcapsules, ${ }^{3}$ coating material for tablets and

Correspondence to: $\mathrm{Md}$. Saiful Islam

Tel: +88-02-9661920-73/8175-76 (Off.), +88-01552455915

Email: saif_phdu@yahoo.com,msipharmacy@du.ac.bd

Dhaka Univ. J. Pharm. Sci. 10(2): 123-129, 2011 (December) granules $^{4-6}$ and matrix forming material for sustained release dosage forms. ${ }^{7,8}$ But EC is considered as an ideal polymer for microencapsulation technology and it has been proved that EC can be used successfully for both oil-in-water and water-in-oil emulsion solvent evaporation technique. ${ }^{9-13}$

Microencapsulation is one process used to control drug release and hence prolong therapeutic activity. ${ }^{14}$ In pharmaceutical sustained release preparations, the uniqueness of microcapsules lies in the wide distribution throughout the gastrointestinal tract. This potentially improves drug absorption and reduces side effects related to localized build-up of irritating drugs against the gastrointestinal mucosa. ${ }^{15}$

In this study, EC was used to prepare sustained release microspheres of NS. Plasticizers at different concentrations were used in the matrix to observe their effect on microsphere properties. However, plasticizer content variation was considered as independent variable and microsphere morphology, size distribution, drug loading, release property of NS were considered as dependent variables. 


\section{MATERIALS AND METHODS}

NS was received as generous gift from SQUARE Pharmaceuticals Ltd., Bangladesh. The following chemicals were obtained from the respective sources and used as received: ethyl cellulose (ETHOCEL 20 cps, Colorcon, UK), polyethyleneglycol 600 (PEG 600, BASF, Germany), polyethyleneglycol 6000 (PEG 6000, BASF, Germany), triethyl citrate (TEC, Morflex Inc. USA), liquid paraffin (Merck, Germany), methanol (Merck, Germany), span 60 (BDH Chemicals, England), petroleum ether of 40:60 grade (Merck, Germany).

Preparation of ethyl cellulose-naproxen sodium microspheres. Microspheres were prepared using the emulsification (water-in-oil) and organic solvent evaporation technique ${ }^{16}$ which is a slight modification of the Tsai technique. ${ }^{17}$
50 gm light liquid paraffin (LLP) and 1\% (wt/wt of the LLP) of span 60 were taken in a beaker (external phase). Drug, polymer and plasticizers (according to table 1) were dissolved in $15 \mathrm{gm}$ methanol (internal phase) and a clear solution was made with the help of a vortex mixer (Digisystem laboratory instruments inc. Taiwan). The internal phase was then incorporated into the external phase with continuous stirring by a high speed stirrer (Heidolph No. 5011, Heidolph, Germany) at 3000 rpm and maintaining the temperature at $25^{\circ} \mathrm{C}$. After 2 hours of stirring, microspheres were filtered and washed with petroleum ether (40:60) for three times and finally dried in a vacuum dryer (Veego, India). Microspheres were then sieved with $1 \mathrm{~mm}$ sieve to remove any lump present.

Table 1. Formulations of naproxen sodium microspheres

\begin{tabular}{lcccccc}
\hline Materials (mg) & F1 & F2 & F3 & F4 & F5 & F6 \\
\hline Naproxen sodium & 2 & 2 & 2 & 2 & 2 & 2 \\
Ethocel 20 cps & 1.8 & 1.8 & 1.8 & 1.2 & 1.2 & 1.2 \\
PEG 600 & 0.2 & & & 0.8 & & \\
PEG 6000 & & 0.2 & & & 0.8 & 0.8 \\
Triethyl citrate (TEC) & & & 0.2 & & & \\
\hline
\end{tabular}

Surface morphology study. To observe the microspheres surface morphology, a Scanning Electron Microscope (SEM, S-3400N, Hitachi, Japan) was used. SEM images at different magnifications were taken for comparative study.

Particle size determination. Microsphere size distribution was analyzed by laser diffraction technique using Mastersizer 2000 (MALVERN, UK). Particle size distribution was measured by Dry dispersion technique. Volume mean diameter (D [4, 3]) was used to express average particle size in $\mu \mathrm{m}$. Specific surface area $\left(\mathrm{m}^{2} / \mathrm{gm}\right)$ of the microspheres was also determined.

Drug content analysis. Aqueous solutions of NS ( 0 to $20 \mu \mathrm{g} / \mathrm{ml}$ ) in phosphate buffer ( $\mathrm{pH}$ 6.8) were prepared and the absorbance was measured at $332 \mathrm{~nm}$ by a Shimadzu UV-VIS Spectrophotometer (UV mini-1240, Shimadzu Corp., Japan). A linear line was obtained while absorbance values were plotted against concentrations $\left(\mathrm{R}^{2}>0.99\right)$.
Drug loaded microspheres of each batch were finely powdered in a glass mortar and $10 \mathrm{mg}$ powder was taken in a volumetric flask. A clear solution was made using the same phosphate buffer after proper sonication (Power Sonic 505, Hwashin Technology Co., Korea). Then the solution was filtered through $0.45 \mu \mathrm{m}$ filter and analyzed spectrophotometrically for drug content. ${ }^{18,19}$

The weight of NS theoretically contained in the microspheres was compared with the weight actually obtained from the drug content studies, i.e., the quantity loaded into the microspheres formulated, to get the NS loading efficiency. ${ }^{20}$ Following equation was used for the calculation.

Drug-loading efficiency $(\%)=\left(\mathrm{C}_{\mathrm{p}} / \mathrm{C}_{\mathrm{t}}\right) \times 100$

where, $\mathrm{C}_{\mathrm{p}}$ and $\mathrm{C}_{\mathrm{t}}$ were the actual and theoretical drug content in NS loaded microspheres of EC polymer, respectively. 
In vitro dissolution study. In vitro dissolution was carried out in a USP XXX apparatus 2 (Paddle Apparatus) in $900 \mathrm{ml}$ phosphate buffer (pH 6.8) at 37 $\pm 0.5^{\circ} \mathrm{C}$ at a rotational speed of $50 \mathrm{rpm}$. Dissolution samples were withdrawn at predetermined intervals and were filtered through $0.45 \mu \mathrm{m}$ filters. The drug content was determined in the filtrate either directly or after appropriate dilution with the dissolution media.

\section{RESULTS AND DISCUSSION}

EC was used as the wall material due to its safety, stability, hydrophobicity and perfect film forming nature among other polymers. Besides, EC has good release retardant property also. ${ }^{21,22}$ However, NS microspheres were successfully prepared by water-in-oil emulsion solvent evaporation technique using EC as the wall material and PEG 600, PEG 6000, TEC as plasticizers.

However, EC microspheres showed good encapsulation efficiency of NS. It was above $85 \%$ for both $10 \%$ and $40 \%$ level of the plasticizers (Table 2). No difference in NS load was seen even though different plasticizers at different ratios were used i.e. variation of plasticizers did not affect the encapsulation efficiency of EC.

Figure 1 shows the SEM photographs of the microsphere formulated using $40 \%$ TEC. Surface appeared smooth at the lower magnification. At higher magnification, microsphere surface appeared embedded with TEC where very few numbers of small pores were seen.

Table 2. Microsphere properties of the optimized batches

\begin{tabular}{|c|c|c|c|c|c|}
\hline \multirow{2}{*}{ Batch } & \multirow{2}{*}{$\mathrm{EE}(\%)^{\mathrm{a}}$} & \multirow{2}{*}{ Particle Mean Diameter $(\mu \mathrm{m})^{\mathrm{b}}$} & \multirow{2}{*}{ SSA $\left(\mathrm{m}^{2} / \mathrm{g} \times 10^{-2}\right)^{\mathrm{c}}$} & \multicolumn{2}{|c|}{ Analysis of "Higuchi” plot } \\
\hline & & & & $\operatorname{SLP}\left(K_{h}\right)^{d}$ & $\mathrm{~K}_{\mathrm{h}} / \mathrm{SSA}$ \\
\hline F1 & 85.36 & $656.14 \pm 18.96$ & 1.34 & 22.23 & 16.58 \\
\hline F2 & 88.44 & $659.19 \pm 19.90$ & 1.34 & 20.52 & 15.31 \\
\hline F3 & 89.34 & $670.64 \pm 17.43$ & 1.25 & 14.23 & 11.38 \\
\hline $\mathrm{F} 4$ & 90.16 & $656.25 \pm 29.54$ & 1.32 & 17.36 & 13.15 \\
\hline F5 & 86.79 & $651.32 \pm 31.12$ & 1.37 & 18.19 & 13.27 \\
\hline F6 & 91.48 & $671.23 \pm 19.23$ & 1.22 & 11.41 & 9.35 \\
\hline
\end{tabular}

${ }^{\mathrm{a}} \mathrm{EE}=$ encapsulation efficiency; ${ }^{\mathrm{b}}$ particle diameter = mean \pm standard deviation; ${ }^{\mathrm{c}} \mathrm{SSA}=$ specific surface area; ${ }^{\mathrm{d}} \mathrm{SLP}=$ slope of Higuchi plot

Microsphere size was $656.14 \mu \mathrm{m}, 659.19 \mu \mathrm{m}$ and $670.64 \mu \mathrm{m}$ for PEG 600, PEG 6000 and TEC at 10\% level of the plasticizers respectively (Table 2). While the plasticizers were used at $40 \%$ level, mean particle sizes were $662.5 \mu \mathrm{m}, 661.32 \mu \mathrm{m}$ and $678.23 \mu \mathrm{m}$ for the plasticizers respectively. Particle size distribution curves of the $10 \%$ plasticizers were unimodal in nature where as those of $40 \%$ plasticizers were little bimodal in nature.

In vitro release of NS from EC microspheres was observed for 8 hours in phosphate buffer of $\mathrm{pH}$ 6.8. Figure 2 shows the zero order release curves of NS. Microspheres were firstly prepared using $10 \%$ of plasticizers and release of NS from these batches is shown in figure 2a. At this level of the plasticizers, almost similar release curves were found for all the plasticizers. Percent release of NS was $93.36 \%$ for PEG 600, 93.02\% for PEG 6000 and 92.67\% for TEC.

However, at $40 \%$ level of the plasticizers, significant differences in the release curves of NS were observed (Figure $2 b$ ). Release was $81.12 \%$ for PEG 600, 70.06\% for PEG 6000 and only 51.12\% for TEC.

PEG is a plasticizer and this plasticizing activity of PEG has been utilized as a good release retardant while used with different types of polymers in different formulations. ${ }^{23-26}$ Due to this plasticizer activity, PEG 600 and PEG 6000 were used in this experiment and they retarded release of NS 

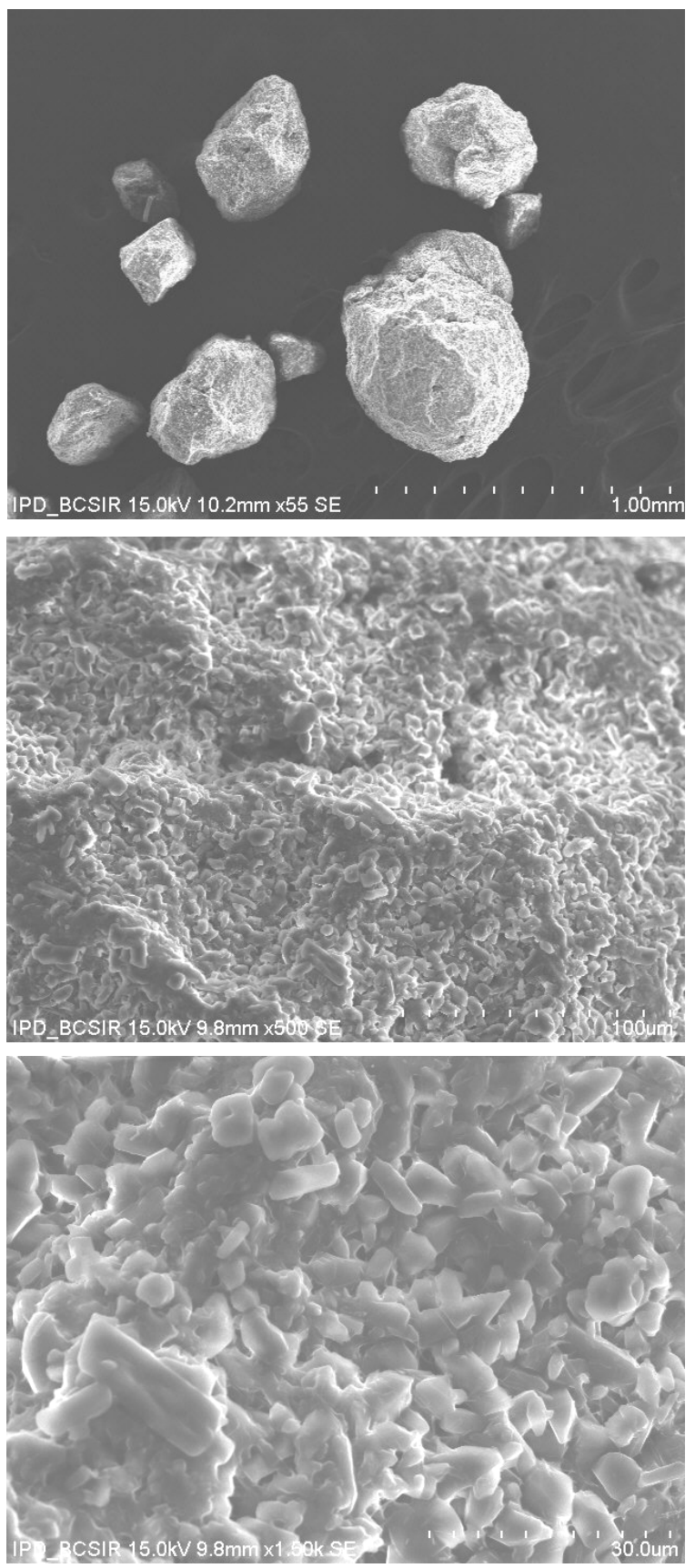

Figure 1. SEM photograph of Ethocel 20cps microspheres of NS containing $40 \%$ of TEC at three different magnifications

significantly specially at $40 \%$ level. But triethyl citrate (TEC) reduced the release of NS mostly. It is a good plasticizer and is the most widely used plasticizer in aqueous and organic film coatings. ${ }^{27-29}$ TEC is also the most compatible plasticizer for the polymer used in this study. TEC reduces the minimum film forming temperature (MFT) of EC more than any other plasticizer. ${ }^{30,31}$ This plasticizer
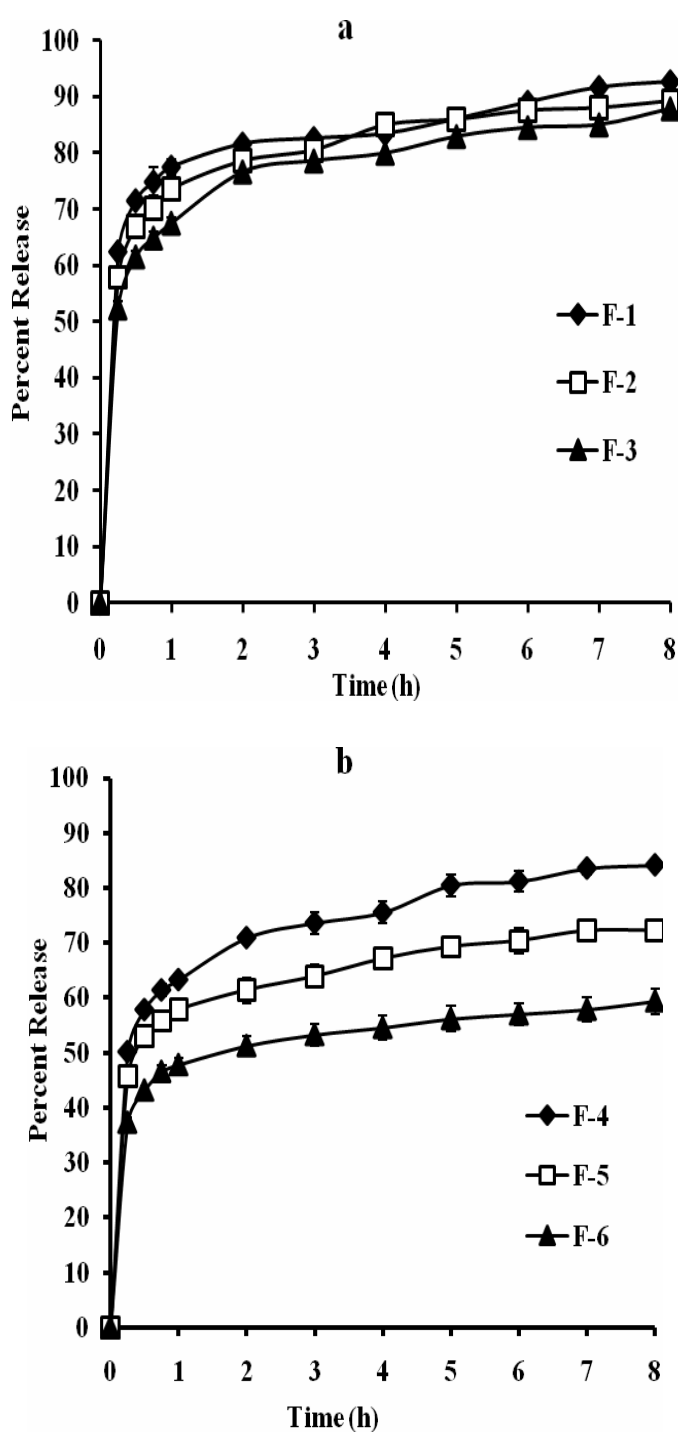

Figure 2. Zero order release of NS from EC microspheres contacting (a) 10\% plasticizers and (b) 40\% plasticizers

has an official monograph in the current USP/NF. ${ }^{32}$ This highly plasticizing activity of TEC might be attributable to the most retarded release of NS from the microsphere formulations. Besides, changes in surface of the microspheres are clearly seen from figure 1 and this also elucidates the release controlling behavior of TEC.

Plasticizers generally are used in different sustained release formulations due to their ability of lowering the glass transition temperature $\left(\mathrm{T}_{\mathrm{g}}\right)$ of different polymers. As the $T_{g}$ of the polymers are lowered, they become more flexible at a 
comparatively lower temperature which ultimately renders the polymers to act as more release retarding agent. For the same purpose, three different plasticizers were considered in this experiment at two different levels. After the addition of the plasticizers at $10 \%$ level in the microsphere formulations, NS release was nearly $90 \%$ after 8 hours for all the plasticizers where almost $75 \%$ of NS was released within first 1 hour. That is, plasticizers at $10 \%$ level were quite unable to delay the initial burst release of the drug. But at $40 \%$ level of the plasticizers, better release was found. At this level, 62\%, 59\% and 48\% drug was released from PEG 600, PEG 6000 and TEC respectively after first hour of dissolution. In figure 4, percent release of NS after 1 hour is shown for $10 \%$ plasticizer (white bars) and $40 \%$ plasticizer (black bars) where it is clearly seen that initial burst release of the drug was successfully delayed due to the presence of higher level of the plasticizers.

Release rates $\left(K_{h}\right)$ of NS were also calculated from Higuchi plots (Figure 3). There was a direct relationship between the rates $\left(\mathrm{K}_{\mathrm{h}}\right)$ and percent excipient contents (Figure 4). Release rates were significantly smaller while the plasticizers were used at $40 \%$ level. When the individual release rates $\left(K_{h}\right)$ were normalized by dividing with the respective microcapsule specific surface area (SSA), there was also a linear relationship between these values ( $\mathrm{K}_{\mathrm{h}} / \mathrm{SSA}$ ) and the percent amount of excipients. These values $\left(\mathrm{K}_{\mathrm{h}} / \mathrm{SSA}\right)$ were found to decrease linearly in the order of PEG 600 PEG 6000 TEC for both $10 \%$ and $40 \%$ level (Table 2).

Time for $50 \%$ drug release $\left(\mathbf{t}_{\mathbf{5 0}}\right), 75 \%$ drug release $\left(\mathbf{t}_{75}\right)$ and mean dissolution time (MDT) were also calculated to assess the kinetic parameters of the release data (Table 3 ). Minimum $t_{50}$ and $t_{75}$ were for PEG 600 comprising formulations. On the other hand, maximum $t_{50}$ and $t_{75}$ were for TEC comprising formulations suggesting that these formulations showed more sustained release activity. MDT value of the formulation comprising TEC was also maximum and it was more than 10 hours.

Table 3. Kinetic parameters of naproxen sodium release curves

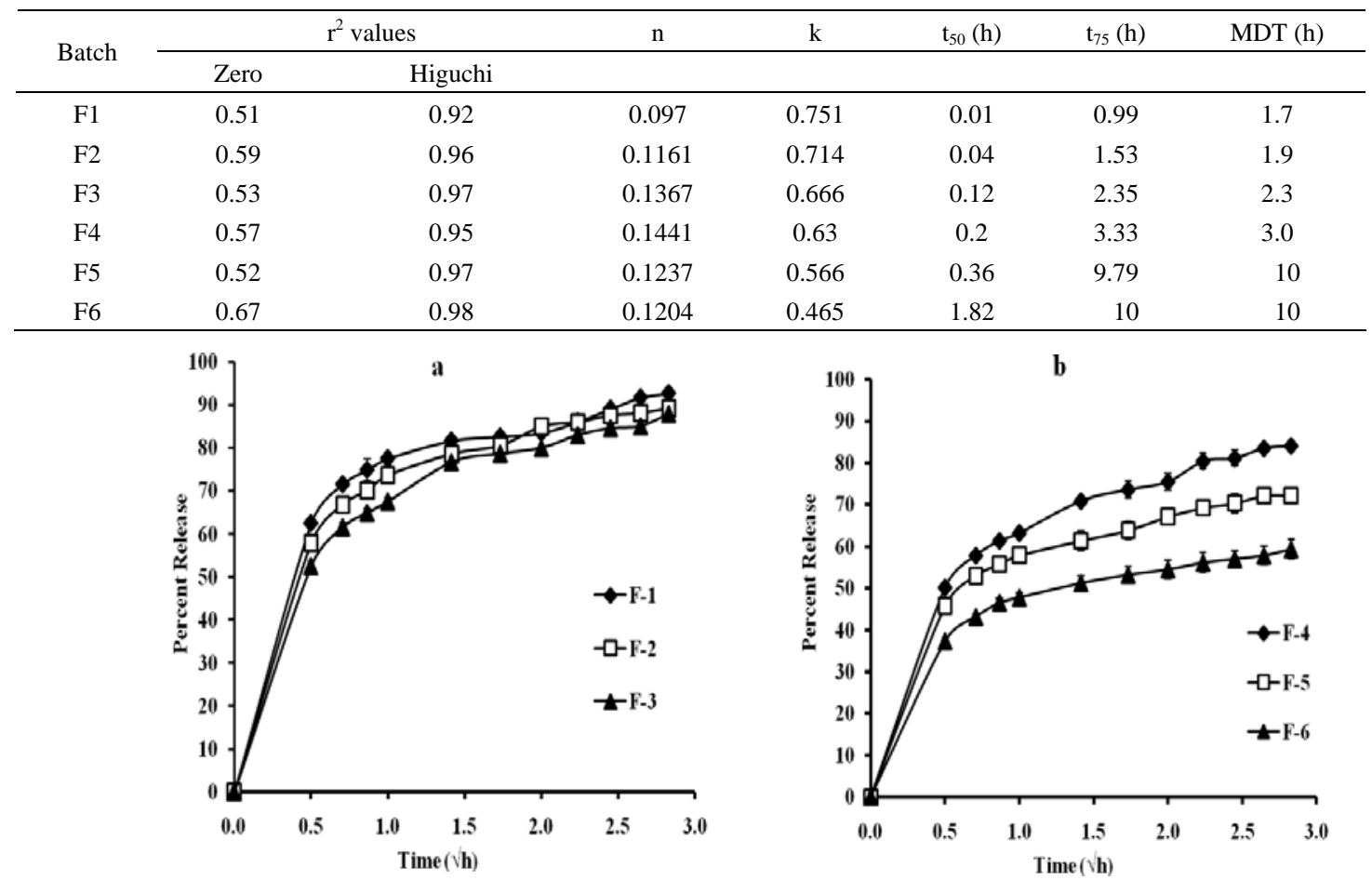

Figure 3. Higuchi release model of NS from EC microspheres contacting (a) 10\% plasticizers and (b) 40\% plasticizers 


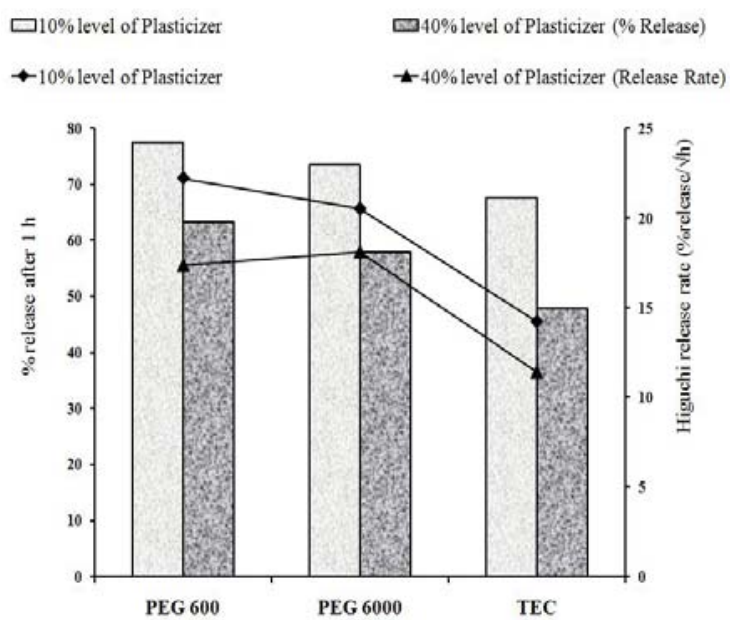

Figure 4. Percent release (bar) and Higuchi release rate (line) of NS from EC microspheres

\section{CONCLUSION}

It can be inferred that Ethocel 20 cps can be a good choice to prepare sustained release microspheres of drugs like NS. Optimized batches showed good drug loading capacity having microsphere size within a satisfactory range. All the plasticizers showed good release controlling capacity. Optimized batches showed good release controlling capacity while containing only $40 \%$ level of plasticizer in their matrix. But, batches formulated with TEC were comparatively better than others. So, Ethocel 20 cps microspheres comprising TEC could be a good choice to release NS for more than 8 hours in the treatment of arthritis.

\section{ACKNOWLEDGEMENTS}

The authors would like to thank SQUARE Pharmaceuticals Ltd., Bangladesh and BASF, Bangladesh for providing the chemicals. They also express their gratitude to Incepta Pharmaceuticals Ltd, Bangladesh for Particle Size Analyzer and Bangladesh Council for Scientific and Industrial Research (BCSIR), for Scanning Electron Microscopic studies.

\section{REFERENCES}

1. Uziel, Y., Hashkes, J.P., Kaseem, E., Padeh, S., Goldman, R., Vollach, B. 2000. The use of naproxen in the treatment of children with rheumatoid fever. J. Pediatr. 137, 269-271.
2. Sajeev, C.G., Vinay, R.A., Saha, R.N. 2002. Oral controlled release formulation of diclofenac sodium by microencapsulation with ethyl cellulose. J. Microcap. 19, 5360.

3. Hashkes, P.J., Tauber, T. 2003. Somekh E, Brik R, Barash J, Mukanel M, Harel L, Lorber A, Berkovitch M, Uziel Y. Naproxen as an alternative to aspirin for the treatment of arthritis of rheumatoid fever: a randomized trial. J. Pediatr. 143, 399-401.

4. Pearnchob, N., Bodmeier, R. 2003. Dry polymer poeder coating and comparison with conventional liquid based coatings for Eudragit RS, ethyl cellulose and shellac. Eur. J. Pharm. Biopharm. 5, 363-369.

5. Sadeghi, F., Ford, J.L., Rajabi, J.L. 2003. The influence of drug type on the release profiles from Surelease coated pellets. Int. J. Pharm. 254, 123-135.

6. Dashevsky, A., Kolter, K., Bodmeier, R. 2004. Compression of pellets coated with various aqueous polymer dispersions. Int. J. Pharm. 279, 19-26.

7. Zabed, I., Almas, B., Muhammad, A. 2002. Controlled release naproxen using micronized ethyl cellulose by wet granulation and solid dispersion method. Drug. Dev. Ind. Pharm. 28, 129-134.

8. Pruthvipathy, R.K., Sthyanarayan, M.U., Steven, H.N., Amit, K.M. 1995. Ethyl cellulose matrix controlled release tablets of water soluble drug. Int. J. Pharm. 123, 119-125.

9. Deasy, P. B. 1984. Microencapsulation and Related Drug Processes (New York: Marcel Dekker, Inc.), pp 361.

10. Kondo, A. 1979. Microencapsulation Processing and Technology, Marcel Dekker, New York.

11. Thies, C. 1995. Kirk-Othmer Encyclopedia of Chemical Technology, Vol. 16, $4^{\text {th }}$ ed., Wiley, pp. 628-651.

12. Finch, C.A. 1990. Ullman's Encyclopedia of Industrial Chemistry, Vol. A16, $5^{\text {th }}$ ed., VCH Publishers, New York, pp. 575-588.

13. Jacobs, I.C., Mason N.S. 1993. In Polymeric Delivery Systems, ACS Symposium Series 520 (M. A. El-Nokaly, D. M. Piatt, and B. A. Charpentier, eds.), American Chemical Society, Washington, DC, p. 1-17.

14. Bakan, J.A., Anderson, J.L. 1976. Microencapsulation: The Theory and Practice of Industrial Pharmacy, edited by L. Lachman, H.A. Lieberman and J.L. Kanig (Philadelphia: Lea and Febiger), pp. 420-438.

15. Li, S.P., Kowalski, C.R., Feld, K.M., Grim, W.M. 1988. Recent advances in microencapsulation technology and equipment. Drug. Dev. Ind. Pharm. 14, 353-376.

16. Jalil, R., Nixon, J.R. 1990. Biodegradable poly(lactic acid) and poly(lactide-co-glycolide) microcapsules: problems associated with preparative techniques and release properties. J. Microencap. 7, 297-325 (Review).

17. Tsai, D.C., Howards, S.A., Hogan, T.F., Malanga, C.J., Kandzari, S.J., Ma, J.K.H. 1986. Preparation and in vitro evaluation of poly (lactic acid)/ mitomycin-c microcapsules, J. Microencap. 3, 181. 
18. Amin, A.F., Gohel, M.C. 1998. Formulation optimization of controlled release diclofenac sodium microspheres using factorial design. J. Control. Release. 51, 115-122

19. Florey, K. 1990. Analytical profiles of drug substances, Academic Press Inc., New York, vol. 19, p. 123.

20. Attama, A.A., Mpamaugo, V.E. 2006. Pharmacodynamics of piroxicam from self-emulsifying lipospheres formulated with homolipids extracted from Capra hircus. Drug Deliv. 13, 133-137.

21. Saadat, S.M.A., Islam, M. S., Jahan, S.T., Chowdhury, J.A., Jalil, R. 2010. Effect of cellulosic and polymethacrylic polymers on drug content, particle morphology, and carbamazepine release profiles from sustained release ethyl cellulose microspheres. Dhaka. Univ. J. Pharm. Sci. 9, 75-82

22. Kibbe, A.H. 2000. Handbook of Pharmaceutical Excipients. $3^{\text {rd }}$ Ed. pp. 1446-63. Washington, D.C.: USA: American Pharmaceutical Association.

23. Ito, F., Fujimori, H., Honnami, H., Kawakami, H., Kanamura, K., Makino, K. 2008. Effect of polyethylene glycol on preparation of rifampicin-loaded PLGA microspheres with membrane emulsification technique. Colloids. Surf. $B$. Biointerfaces. 66, 65-70.

24. Nande, V.S., Barabde, U.U., Morkhade, D.M., Patil, A.T., Joshi, S.B. 2007. Sustained release microspheres of diclofenac sodium using PEGylated rosin derivatives. Drug. Dev. Ind. Pharm. 33, 1090-100.
25. Morkhade, D.M., Nande, V.S., Barabde, U.V., Patil, A.T., Joshi, S.B. 2007. PEGylated rosin derivatives: Novel microencapsulating materials for sustained drug delivery. AAPS PharmSciTech, 22, 8, Article 47.

26. Park, E.J., Na, D.H., Lee, K.C. 2007. In vitro release study of mono-PEGylated growth hormone-releasing peptide-6 from PLGA microspheres. Int. J. Pharmaceutics. 1, 343, 281-3.

27. Abbaspour, M.R., Sadeghi, F., Afrasiabi G. H. 2008. Design and study of ibuprofen disintegrating sustained-release tablets comprising coated pellets. Eur. J. Pharm. Biopharm. 68, 747-759.

28. Kucera, S.A., Stimpel, D., Shah, N.H., Malick, A.W., Infeld, M.H., McGinity, J.W. 2008. Influence of fumed silicon dioxide on the stabilization of Eudragit RS/RL 30 D filmcoated theophylline pellets. Pharm. Dev. Technol. 13, 245-253.

29. Shao, Z.J., Moralesi, L., Diaz, S., Muhammadi, N.A. 2002. Drug release from Kollicoat SR 30D-coated nonpareil beads: Evaluation of coating level, plasticizer type, and curing condition. AAPS PharmSciTech. 3, E15.

30. BASF, Technical Information, April 2006.

31. Kojima, M., Nakagami, H. 2000. Development of controlled release matrix pellets by annealing with micronized waterinsoluble or enteric polymers. J. Control. Release. 21; 82, 335-43.

32. U.S.P. 1995. 23/NF 18, "Triethyl Citrate-Official Monograph", p. 2316. 